\title{
Relationship between Whole Plasma Calcitonin Levels, Calcitonin Secretory Capacity, and Plasma Levels of Estrone in Healthy Women and Postmenopausal Osteoporotics
}

\author{
J. Y. Reginster, R. Deroisy, A. Albert, D. Denis, M. P. Lecart, J. Collette, and P. Franchimont \\ Bone Metabolism Unit, Department of Rheumatology and Physical Medicine, Policlinique L. Brull, \\ University of Liège, 4020 Liège, Belgium
}

\begin{abstract}
The exact role of calcitonin (CT) in the pathogenesis of postmenopausal osteoporosis remains unknown. Whole plasma calcitonin (iCT) basal levels, metabolic clearance rate (MCR), and production rate (PR) of $C$ Tere measured in 9 premenopausal and 16 postmenopausal women, including 11 osteoporotics (OP). Basal iCT levels were statistically lower in postmenopausal women than in the premenopausal group ( $P$ $<0.01)$ and strongly correlated $(r=0.72 ; P<0.001)$ with estrone circulating levels (E1). MCR were similar in all groups. PR were similar in eugonadal women between 22 $($ mean \pm SD $=30.9 \pm 9.9 \mu \mathrm{g} / \mathrm{d})$ and $37 \mathrm{yr}($ mean $\pm S D$ $=25.5 \pm 11.1 \mu \mathrm{g} / \mathrm{d}$ ) premenopausal women. In healthy postmenopausal women $P R$ were reduced, but not significantly $($ mean \pm SD $=19.5 \pm 6.95 \mu \mathrm{g} / \mathrm{d})$, whereas osteoporotic patients presented a highly significant reduction of CT PR (mean \pm SD $=9.8 \pm 4 \mu \mathrm{g} / \mathrm{d})(P<0.01)$. Because there is a strong relationship between E1 and PR $(r=0.64 ; P<0.001), C T$ secretory capacity appears to be modulated by estrogen circulating levels. This modulation leads to a menopause-related decrease in iCT. In osteoporotics, an independent impairment of CT production drastically lowers PR and basal iCT levels. CT might be one of the determining factors in the pathogenesis of postmenopausal osteoporosis.
\end{abstract}

\section{Introduction}

Calcitonin $(\mathrm{CT})^{1}$ has been known for many years to inhibit osteoclastic resorption of bone $(1,2)$. Therefore, CT is frequently used for treatment of metabolic bone diseases characterized by increased bone turnover (3). Recently, CT has been

Address reprint requests to Dr. Jean-Yves Reginster, Bone Metabolism Unit, Rheumatology and Physical Medicine Unit, Policlinique L. Brull (+9), Quai Godefroid Kurth, 45, 4020 Liège, Belgium.

Received for publication 14 September 1988 and in revised form 9 November 1988.

1. Abbreviations used in this paper: $\mathrm{CT}$, calcitonin; $\mathrm{CV}$, coefficient of variation; E1, estrone; iCT, whole plasma immunoreactive calcitonin; MCR, metabolic clearance rate; OP, osteoporosis; PR, production rate.

J. Clin. Invest.

(c) The American Society for Clinical Investigation, Inc.

0021-9738/89/03/1073/05 \$2.00

Volume 83, March 1989, 1073-1077 shown to reduce postmenopausal bone loss (4) and to potentially restore decreased bone mass (5).

However, notwithstanding the therapeutic effect of CT on bone diseases, the exact role of CT in the pathogenesis of postmenopausal osteoporosis (OP) remains controversial. CT concentrations have been reported to be lower in women than in men, regardless of the assay method $(6,7)$. Some investigators have suggested that calcitonin secretion may decline at the menopause (8) and be stimulated by estrogen (9), although this is not yet generally accepted (10). A decreased immunoreactive calcitonin response to calcium infusions has also been described in postmenopausal osteoporotic women, suggesting that calcitonin deficiency may be involved in the development of postmenopausal osteoporosis (11).

In this study, we investigated the relationship between age or menopause with CT secretory capacity and the influence of plasma estrone (E1) levels on CT secretory capacity. We also investigated whether osteoporotic patients have absolute or relative $C T$ deficiency.

\section{Methods}

Patients. 24 female subjects completed the entire experimental procedure. Informed consent was obtained from all subjects before the trial, which had the prior approval of the Local Ethical Committee.

Subjects were divided into four groups. Group I consisted of five subjects aged 19-23 yr old (mean \pm SD: 22.6 \pm 2 ). Group II consisted of four subjects aged $35-40$ yr old (mean \pm SD: $37.5 \pm 2.3$ ). All nine subjects were eugonadal. They had never received any exogenous sex hormones and were known to have regular menstruations. No pregnancy had occurred for $>5$ yr. In groups 1 and 2, the test was performed twice during the menstrual cycle: late follicular phase on day 12 and luteal phase on day 22. Because the results of the two tests did not differ significantly, data were pooled, giving 10 values in group I and 8 values in group II.

Group III consisted of four healthy postmenopausal subjects, 53-74 yr old (mean \pm SD: 68 \pm 9.2 ). Group IV consisted of 11 agematched postmenopausal osteoporotics (OP), 57-83 yr old (mean \pm SD: 71 \pm 7.4 ). OP was defined by the existence of at least one nontraumatic crushed vertebra on a lateral $x$-ray view. None of the group IV subjects had ever received treatment before the time of the trial. All subjects had normal renal function as judged by plasma creatinine and urea.

Determination of calcitonin and estrone levels. Blood samples were immediately centrifuged and stored at $-20^{\circ} \mathrm{C}$ for the subsequent determination of the whole plasma immunoreactive calcitonin (iCT) and plasma estrone (E1). All samples were measured in the same assay. Plasma iCT was determined by RIA previously described involving synthetic human calcitonin labeled with ${ }^{125} \mathrm{I}$ by the chloramine $\mathrm{T}$ method (12). The antiserum was directed against the 11-32 COOH-ter- 
minal prolinamide group. There was no cross-reaction with salmon and porcine calcitonin. The limit of detection of this assay was 15 $\mathrm{pg} / \mathrm{ml}$. Concentrations equal to or greater than this depressed the percentage of labeled tracer bound to antibody, at least 2 SD more than the binding obtained in the absence of unlabeled CT. The intraassay coefficient of variation $(\mathrm{CV})$ was $3 \%$ and the interassay $\mathrm{CV}$ was $<10 \%$ of the mean. The plasma estrone (E1) concentrations were determined using an ${ }^{125}$ I-estrone kit from Diagnostic Biomedicals Canada, Inc. (London, Ontario, Canada). The intra- and interassay coefficients of variation were $<8$ and $12 \%$, respectively. The sensitivity of the assay was $\sim 10 \mathrm{pg}$ per tube. The cross-reactivity of estradiol and estriol was $<0.1 \%$ and the nonspecific binding was $<5 \%$.

Experimental procedure. E1 was measured at the beginning of the experimental procedure. The procedure for determination of subjects' production rate (PR) and metabolic clearance rate (MCR) of CT followed the outline proposed by Kanis et al. (13). After an overnight fast, two intravenous lines were established in opposite forearm veins while the subjects were lying supine, one for the infusion of human calcitonin and the other for the withdrawal of blood for plasma iCT determination. An intravenous infusion of $0.9 \%$ sodium chloride solution (154 $\mathrm{mmol} /$ liter) $(0.5 \mathrm{ml} / \mathrm{min})$ was given by electric pump for a period of $1 \mathrm{~h}$. Baseline blood samples were withdrawn for measurement of iCT 15, 30, 45, and $60 \mathrm{~min}$ after the start of the infusion. After $60 \mathrm{~min}$, the infusion of saline was substituted by an infusion of synthetic human calcitonin (rate of infusion: $20 \mu \mathrm{g} / \mathrm{h}$ ) (Ciba Geigy, Basel, Switzerland) in a similar volume of saline with added albumin $(0.25 \mathrm{~g} / 100$ $\mathrm{ml}$ ). The infusion of CT was performed for $2 \mathrm{~h}$, followed by infusion of the initial saline solution for $1 \mathrm{~h}$. Blood samples were withdrawn at intervals of $15 \mathrm{~min}$. Plasma levels of iCT rose progressively at the start of infusion and reached a maximum level after $1 \mathrm{~h}$, which was maintained throughout the course of the infusion.

Basal iCT plasma concentrations were determined by the mean of values obtained at the beginning of the experimental procedure and after 15, 30, 45, and $60 \mathrm{~min}$ of saline solution perfusion. Steady-state plasma levels were calculated in individual patients as the mean of the four iCT determinations taken during the second hour of the infusion of human calcitonin.

The MCR was calculated from the formula (14): $M C R=$ rate of infusion/steady-state plasma level. The endogenous $P R$ was calculated from the formula: $\mathrm{PR}=\mathrm{MCR} \times$ basal plasma concentration.

Statistical analysis. Data were normalized using a log-transformation for statistical analysis. Groups were compared using analysis of variance (ANOVA) and individual differences were assessed by means of simultaneous confidence intervals. This methodology made possible the analysis of small-sized samples like group III. As indicated previously, patient' data regarding follicular and luteal phases were not different and were therefore merged so as to increase the sample size. We verified that ANOVA performed on all six groups (with follicular and luteal phases considered separately in groups I and II) or in four groups (follicular and luteal phases of groups I and II pooled) yielded identical conclusions.

A linear regression analysis was performed to investigate the relationship between plasma E1, age, CT plasma basal levels, and CT production rates (15).

\section{Results}

All basal plasma iCT determinations were within the detection limit of the assay $(>15 \mathrm{pg} / \mathrm{ml})$ and stay within the normal range for our lab $(<120 \mathrm{pg} / \mathrm{ml})$ (Table I). Mean basal levels were not statistically different between group I (mean \pm SD $=84.2 \pm 18.4 \mathrm{pg} / \mathrm{ml})$ and group II $($ mean $\pm \mathrm{SD}=74.2 \pm 24.7$ $\mathrm{pg} / \mathrm{ml}$ ) or between group III (mean $\pm \mathrm{SD}=47.5 \pm 19.5 \mathrm{pg} / \mathrm{ml}$ ) and group IV (mean $\pm \mathrm{SD}=32.3 \pm 9.8 \mathrm{pg} / \mathrm{ml}$ ) (Fig. 1). Using the ANOVA analysis, iCT basal levels in groups I and II were
Table I. Individual and Mean Values \pm SD for Plasma Basal iCT, MCR (CT), PR (CT), and Plasma Basal EI

\begin{tabular}{ccccc}
\hline Subjects & Basal CT & MCR (CT) & PR (CT) & Basal E1 \\
\hline & $p g / m l$ & liters $/ 24 h$ & $\mu g / 24 h$ & $n g /$ liter \\
Group I & & & & \\
1 & 86 & 269 & 23 & 58 \\
2 & 104 & 412 & 43 & 156 \\
3 & 74 & 357 & 26 & 140 \\
4 & 86 & 386 & 33.2 & 63 \\
5 & 86 & 325 & 28 & 129 \\
6 & 50 & 356 & 18 & 104 \\
7 & 83 & 554 & 46 & 37 \\
8 & 71 & 328 & 23.3 & 57 \\
9 & 119 & 366 & 43.6 & 123 \\
10 & 83 & 307 & 25.5 & 126 \\
Mean \pm SD & $84.2 \pm 18.4$ & $366 \pm 77.5$ & $30.9 \pm 9.9$ & $99.3 \pm 41.8$
\end{tabular}

\section{Group II}

$\begin{array}{lrccc}1 & 49 & 322 & 16 & m \\ 2 & 81 & 325 & 26 & 60 \\ 3 & 102 & 377 & 38 & 100 \\ 4 & 104 & 400 & 42 & 151 \\ 5 & 85 & 297 & 25 & 73 \\ 6 & 70 & 433 & 30 & 83 \\ 7 & 71 & 252 & 18 & 86 \\ 8 & 32 & 280 & 9 & m \\ \text { Mean } \pm \text { SD } & 74.2 \pm 24.7 & 335.7 \pm 62.3 & 25.5 \pm 11.1 & 92.1 \pm 31.7\end{array}$

Group III

$\begin{array}{ccccc}1 & 42 & 373 & 16 & m \\ 2 & 25 & 520 & 13 & 19 \\ 3 & 51 & 389 & 20 & 60 \\ 4 & 72 & 401 & 29 & 29 \\ \text { Mean } \pm \text { SD } & 47.5 \pm 19.5 & 420 \pm 67 & 19.5 \pm 6.95 & 36 \pm 21\end{array}$

$\begin{array}{cccrc}\text { Group IV } & & & & \\ 1 & 25 & 298 & 7.5 & m \\ 2 & 34 & 274 & 9.3 & 22 \\ 3 & 52 & 355 & 18.5 & 52 \\ 4 & 26 & 337 & 8.7 & 50 \\ 5 & 25 & 273 & 6.8 & 22 \\ 6 & 25 & 296 & 7.4 & 30 \\ 7 & 25 & 250 & 6.3 & 29 \\ 8 & 34 & 303 & 10.3 & m \\ 9 & 33 & 287 & 9.5 & m \\ 10 & 49 & 339 & 16.6 & 21 \\ 11 & 27 & 275 & 7.4 & 32 \\ \text { Mean } \pm \text { SD } & 32.3 \pm 9.8 & 298.9 \pm 32.6 & 9.8 \pm 4 & 32.2 \pm 12.9\end{array}$

$m$, missing data.

statistically higher than that of groups III and IV. No significant correlation was found between the age of the subjects and basal plasma iCT in the two groups of premenopausal women or in the groups constituted by postmenopausal subjects or in the entire population.

Calculated MCR in groups I (mean $\pm \mathrm{SD}=366 \pm 77.5$ liter/ $24 \mathrm{~h})$, II (mean \pm SD $=335.7 \pm 62.3$ liter $/ 24 \mathrm{~h})$, III (mean \pm SD $=420 \pm 67 \mathrm{liter} / 24 \mathrm{~h}$ ), and IV (mean $\pm \mathrm{SD}=298.9 \pm 32.6 \mathrm{liter} /$ $24 \mathrm{~h}$ ) were not significantly different (Fig. 1). 

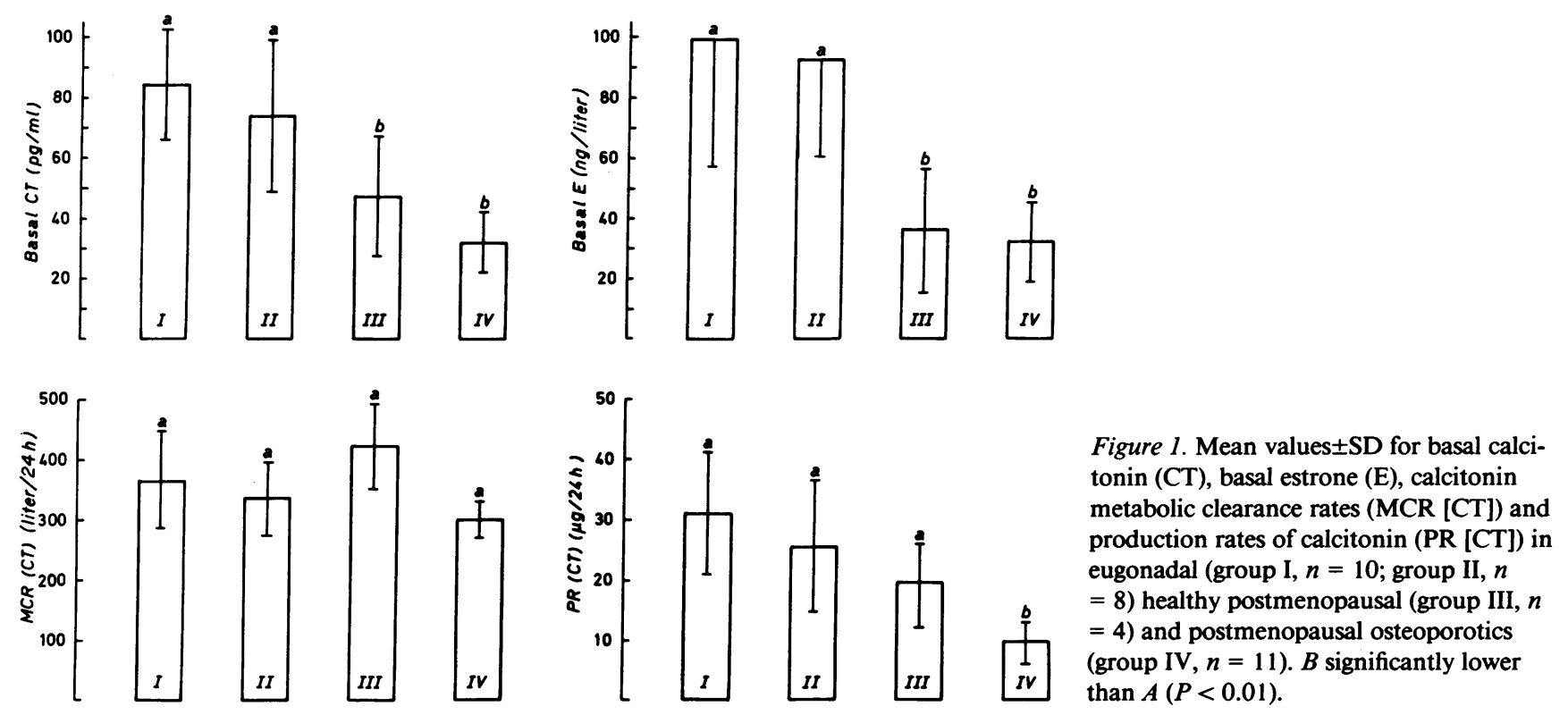

PR of CT were within the same range in groups I $($ mean \pm SD $=30.9 \pm 9.9 \mu \mathrm{g} / 24 \mathrm{~h})$, II (mean \pm SD $=25.5 \pm 11.1$ $\mu \mathrm{g} / 24 \mathrm{~h}$ ), and III (mean \pm SD $=19.5 \pm 6.95 \mu \mathrm{g} / 24 \mathrm{~h}$ ), whereas values obtained in group IV (mean \pm SD $=9.8 \pm 4 \mu \mathrm{g} / 24 \mathrm{~h}$ ) were significantly decreased (Fig. 1). Linear regression relationship did not show any statistically significant difference between age of the subjects and PR of CT in any of the two groups of premenopausal women or in the groups constituted by postmenopausal subjects or in the whole population.

Plasma E1 levels were measured during 27 out of 33 procedures performed in 24 subjects. Plasma estrone levels were not significantly different in groups $I$ (mean $\pm S D=99.3 \pm 41.8$ $\mathrm{ng} /$ liter) and II (mean $\pm \mathrm{SD}=92.1 \pm 31.7 \mathrm{ng} /$ liter) but groups I and II were significantly higher than group III (mean \pm SD $=36 \pm 21 \mathrm{ng} /$ liter) and group IV (mean $\pm \mathrm{SD}=32.2 \pm 12.9 \mathrm{ng} /$ liter) in which all values were within the same range (Fig. 1).

Linear regression analysis showed a significant correlation both between basal levels of iCT and E1 values ( $r=0.73$ and $P$ $<0.001$ ) (Fig. 2) and between PR of CT and plasma E1 ( $r$ $=0.64$ and $P<0.001$ ) (Fig. 3).

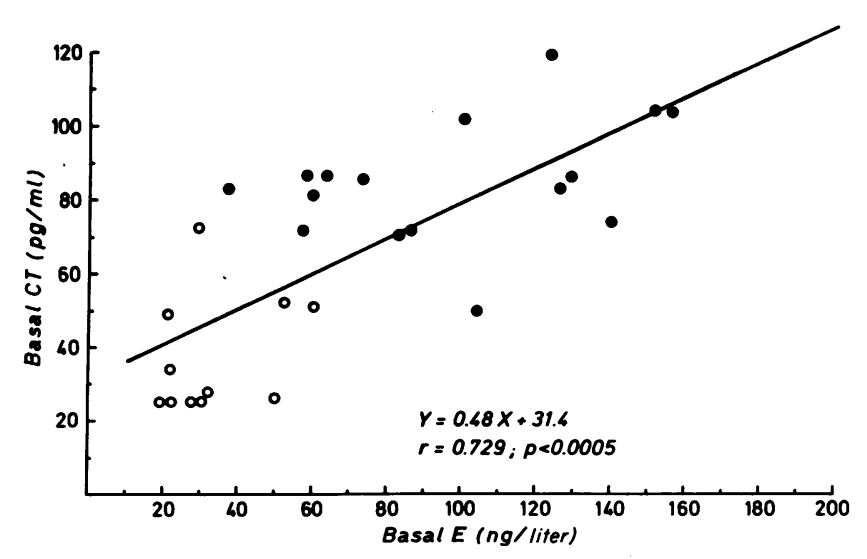

Figure 2. Relationship between basal plasma estrone levels (E) and basal whole plasma calcitonin levels (CT). •, eugonadal women; $\circ$, postmenopausal women.

\section{Discussion}

Several discrepancies about the validity of whole plasma CT determinations currently exist between authors. CT circulates in the plasma in heterogeneous forms $(16,17)$ and whole CT assays cross-react with several fragments of larger molecular weight than native monomeric CT (18). As it is possible, but not proved, that some of these immunoreactive CT forms do not possess biological activity, whole CT assays might overestimate the fraction of plasma calcitonin with biological activity. However, it is still unclear whether fragments of lower or higher molecular weight than monomeric 1-32 calcitonin are completely deprived of inhibiting activity on osteoclasts. In this study we use an assay for iCT with high sensitivity, characterized by a lower limit of detection $(<15 \mathrm{pg} / \mathrm{ml})$ and a maximal normal value of $120 \mathrm{pg} / \mathrm{ml}$. With such an assay, no subject was found to have undetectable basal plasma iCT and all results for basal iCT were within the normal range.

Conflicting data exist on the respective effects of age or menopause on basal iCT levels $(7,8)$. Several authors $(19,20)$

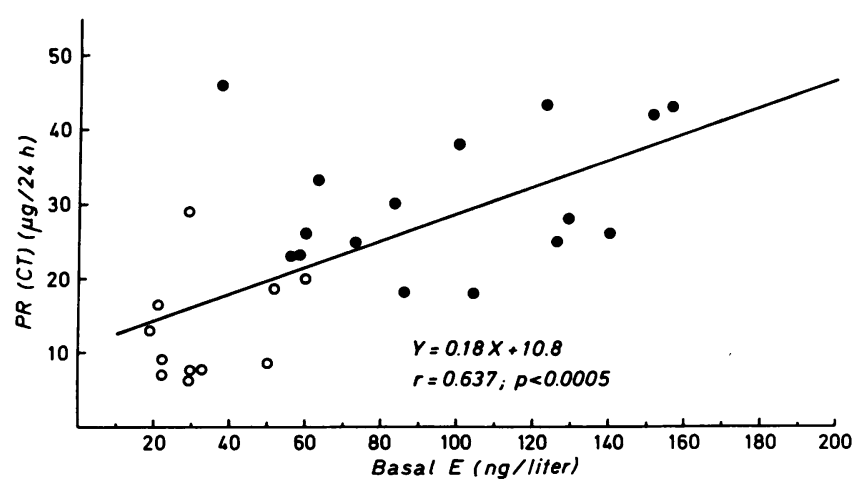

Figure 3. Relationship between basal plasma estrone levels (E) and production rates of calcitonin (PR [CT]). ๑, eugonadal women; $\bigcirc$, postmenopausal women. 
found that women had lower iCT concentrations than men. In our study, premenopausal women did not show any decrease in basal iCT between 22 and $37 \mathrm{yr}$, but after menopause, basal iCT levels are significantly decreased independent of the existence of osteoporosis.

Our values of CT MCR are slightly lower than described by previous reports. Assuming a mean weight of $65 \mathrm{~kg}$ for females, previous data reported MCR values of $\sim 750$ liters $/ 24$ $\mathrm{h}$ for subjects $<30 \mathrm{yr}$ old and 550 liters $/ 24 \mathrm{~h}$ for subjects $>50$ yr old, using the iCT assay (7). In this study, the changes in MCR throughout life were not statistically modified by menopause or age. This is consistent with our findings presented here. In our osteoporotic group, the mean values were not statistically different from those obtained in healthy women.

Few estimates of the CT production rates are available in human subjects. Using the same rate of monomeric CT infusion $(20 \mu \mathrm{g} / \mathrm{kg})$, Kanis et al. (13) found PR of CT three to four times higher than that found in our healthy population. Their assay gave undetectable results in $20 \%$ of normal subjects and a maximum normal value of $980 \mathrm{pg} / \mathrm{ml}$, which may lead to a greater overestimation of CT circulating levels than does the assay used in our study. Tiegs et al. (7), using an assay with properties more similar to ours, described normal female subjects as having PR of $304 \mathrm{ng} / \mathrm{d} \cdot \mathrm{kg}^{-1}$ between 21 and $29 \mathrm{yr}$ old and $229 \mathrm{ng} / \mathrm{d} \cdot \mathrm{kg}^{-1}$ between 55 and $70 \mathrm{yr}$ old. Assuming a mean body weight of $65 \mathrm{~kg}$ for females, their results are in close accordance with our data, corresponding respectively to 20 $\mu \mathrm{g} / 24 \mathrm{~h}$ in young females and $15 \mu \mathrm{g} / 24 \mathrm{~h}$ in old females, with a gap of $\pm 30 \%$ from our data. Plasma CT PR remains relatively constant between 22 and $37 \mathrm{yr}$ of age, as was seen for plasma basal iCT. No relationship appears between basal iCT or CT $P R$ and age either in eugonadal women or in postmenopausal subjects.

The lack of a significant CT PR decrease in the presence of a reduction in basal iCT levels in healthy postmenopausal women (group III) compared with premenopausal women (groups I and II) is probably related to the small size of our sample and the relatively wide range of PR values.

This study is the first report of measurement of CT PR in a population of osteoporotic women. Group IV shows production rates of CT drastically reduced. This decrease is significant with respect to groups I, II, and III. Values of CT PR in group IV are reduced to one third of production rates of calcitonin measured in young healthy females and to one half of those reported in healthy age-matched postmenopausal women. These results are in conflict with the measurements of basal calcitonin (10) or calcitonin secretory reserve (21) previously reported to be normal or high in postmenopausal osteoporosis.

Plasma E1 levels reflect the menopausal status of our subjects. The values of $\mathrm{E} 1$ are high in eugonadal women. We expect plasma $\mathrm{E} 1$ to be high reflecting normal ovarian function, because we excluded women with irregular menstruations or previous history of gynecological dysfunction. Our experimental procedures were performed on days 12 and 22 of the menstrual cycle corresponding to late follicular and luteal phases, respectively, in which basal plasma E1 levels are reported to be high and within the same range (22). Low values of plasma El found in our postmenopausal groups were not surprising because these women (mean age: $68 \mathrm{yr}$ ) had been postmenopausal for several years. This elapsed time span in menopause results in the disappearance of high $\mathrm{E} 1$ levels due to a remanent ovarian secretion, as commonly seen during the first years of menopause. Plasma E1 values reported here in postmenopausal women are probably related to peripheral aromatization of circulating androgens, specifically androstenedione, produced by adrenal glands, into estrone (23).

In our population, there was a direct relationship ( $P$ $<0.001$ ) between basal E1 levels and basal iCT levels as well as CT PR suggesting an influence of estrogenic secretion on calcitonin metabolism. This confirms previous studies (8) showing that deficiency in serum estrogen is associated with a decrease in serum basal iCT.

Because no age-related decrease appeared in eugonadal women or in postmenopausal women, our data, support the findings of Tiegs et al. (7) and suggest that age by itself does not play a major determinant influence on iCT secretory capacity, at least within groups in which E1 levels remain in the same range.

E1 levels are not statistically different in groups III and IV but CT production rates are collapsed in group IV. It may be assumed that this fall of secretory capacity of CT in osteoporotic patients involves not only a menopause-related phenomenon, like group III, but also a specific pathway that does not occur in healthy women. Because group IV has also the lowest CT MCR, this specific impairment of CT metabolism cannot be related to an excessive catabolism of the hormone but, more likely, to a defect in CT production or secretion.

In conclusion, in an eugonadal women population, as long as E1 circulating levels remain high, no evidence appears that CT secretory capacity might be decreased by an age-related mechanism. But in our two groups of postmenopausal women, healthy or osteoporotic, there was a fall in plasma circulating E1 levels leading through a menopause-related effect to a reduction of CT secretory capacity. This reduction of CT secretion, whereas MCR remain constant, leads to a reduction in iCT basal levels in postmenopausal women compared with premenopausal women. Furthermore, because osteoporotic patients presented a highly significant reduction of CT production rates even when compared with healthy patients matched for age and E1 levels, it is probably that in addition to the menopause-related effect, this reduction of CT secretory capacity in osteoporotics has to be related to a specific and still unknown impairment of CT metabolism.

These findings describe for the first time CT secretory capacity in an osteoporotic population. These results provide a better understanding of the role of CT in the pathogenesis of postmenopausal osteoporosis and help to consider prevention and treatment of osteoporosis by CT not only as a pharmacological but also as a etiopathogenic therapy.

\section{References}

1. Friedman, J., and L. G. Raisz. 1965. Thyrocalcitonin, inhibitor of bone resorption in tissue culture. Science (Wash. DC). 150:14651467.

2. O'Riordan, J. L., and G. D. Aurbach. 1966. Mode of action of thyrocalcitonin. Endocrinology. 82:377-383.

3. Bijvoet, O. L. M., J. Van Der Sluys Veer, and A. P. Jensen. 1968. Effects of calcitonin on patients with Paget's disease, thyrotoxicosis and hypercalcemia. Lancet. i:876-881.

4. Reginster, J. Y., D. Denis, A. Albert, R. Deroisy, M. P. Lecart, M. A. Fontaine, P. Lambelin, and P. Franchimont. 1987. 1-year controlled randomized trial of prevention of early postmenopausal bone loss by intranasal calcitonin. Lancet. ii: 1481-1483.

5. Gennari, C., S. M. Chierichetti, S. Bigazzi, L. Fusi, S. Gonnelli, 
R. Ferrara, and F. Zacchei. 1985. Comparative effects on bone mineral content of Calcium plus Salmon Calcitonin given in two different regimens in postmenopausal osteoporosis. Curr. Ther. Res. 38:455464.

6. Hillyard, C. J., J. C. Stevenson, and I. Macintyre. 1978. Relative deficiency of plasma-calcitonin in normal women. Lancet. ii:961-962.

7. Tiegs, R. D., J. J. Body, J. M. Barta, and H. Heath III. 1986. Secretion and metabolism of monomeric human calcitonin: effects of age, sex and thyroid damage. J. Bone Miner. Res. 1:339-349.

8. Lore, F., M. Galli, B. Franci, and M. T. Martorelli. 1984. Calcitonin levels in normal subjects according to age and sex. Biomed.\& Pharmacother. 38:261-263.

9. Stevenson, J. C., G. Abeyasekara, C. J. Hillyard, K. G. Phang, I. Macintyre, S. Campbell, G. Lane, P. T. Townsend, O. Young, and M. I. Whitehead. 1983. Regulation of calcium-regulating hormone by exogenous sex steroids in early menopause. Eur. J. Clin. Invest. 13:481-487.

10. Chesnut, C. H. III, D. J. Baylink, K. Sisom, W. B. Nelp, and B. A. Roos. 1980. Basal plasma immunoreactive calcitonin in postmenopausal osteoporosis. Metab. Clin. Exp. 29:559-562.

11. Taggart, H. McA., J. L. Ivey, K. Sisom, C. H. Chesnut III, D. J. Baylink, and M. B. Huber. 1982. Deficient calcitonin response to calcium stimulation in postmenopausal osteoporosis? Lancet. i:475478.

12. Heynen, G., and P. Franchimont. 1974. Human calcitonin radioimmunoassay in normal and pathological conditions. Eur. J. Clin. Invest. 4:213-222.

13. Kanis, J. A., G. Heynen, T. Cundy, F. Cornet, A. Paterson, and R. G. G. Russel. 1982. An estimate of the endogenous secretion rate of calcitonin in man. Clin. Sci. 63:145-152.

14. Tait, J. F. 1978. Review: the use of isotopic steroids for the measurement of production rates in vivo. Anal. Biochem. 90:1-12.
15. Dixon, W. J., and F. J. Fr. Massey. 1985. Introduction to statistical analysis. 4th ed. McGraw-Hill Book Co., Singapore. 678 pp.

16. Deftos, L. J., B. A. Roos, D. Bronzert, and J. G. Parthemore. 1975. Immunochemical heterogeneity of calcitonin in plasma. J. Clin Endocrinol. \& Metab. 40:409-412.

17. Singer, F. R., and J. F. Habener. 1974. Multiple immunoreactive forms of calcitonin in human plasma. Biochem. Biophys. Res. Commun. 61:710-716.

18. Heynen, G., J. C. Hendrick, and P. Franchimont. 1975. Heterogeneity of calcitonin in human serum. In Vitamin D and Problems Related to Uraemic Bone Disease. A. W. Norman, K. Schaeffer, H. G. Grigoleit, D. V. Herrath, and E. Ritz, editors. E. de Gruytter Publishers. Berlin. 475-481.

19. Heath, H. III, and G. W. Sizemore. 1977. Plasma calcitonin in normal man: difference between men and women. J. Clin. Invest. 60:1135-1140.

20. Deftos, L. J., M. H. Weisman, G. W. Williams, D. B. Kerpf, A. M. Frumar, B. J. Davidson, J. G. Parthemore, and H. L. Judd. 1981. Influence of age and sex on plasma calcitonin in human beings. N. Engl. J. Med. 302:1351-1353.

21. Tiegs, R. D., J. J. Body, H. W. Wahner, J. Barta, B. L. Riggs, and H. Heath III. 1985. Calcitonin secretion in postmenopausal osteoporosis. N. Engl. J. Med. 312:1097-1100.

22. Cook, C. L., C. V. Rao, and M. A. Yussman. 1983. Plasma gonadotropin and sex steroid hormone levels during early, midfollicular, and midluteal phases of women with luteal phase defect. Fertil. Steril. 40:45-47.

23. Forney, J., L. Miewich, G. Chen, J. Garlock, B. Schwarz, C. Edman, and P. McDonald. 1981. Aromatization of androstenedione to estrone by human adipose tissue in vitro. Correlation with adipose tissue mass, age and endometrial neoplasia. J. Clin. Endocrinol. \& Metab. 53:192-199. 